\title{
COMERCIANTES, CORREDORES y MARCHANTES: EL MERCADO ORIENTAL DE MANAGUA COMO ESPACIO DE INTERACCIÓN SOCIAL ${ }^{1}$
}

Norling Solís Narváez

\begin{abstract}
Resumen.
El Mercado Oriental de Managua es un espacio ambiguo, en el cual conviven lo moderno y lo tradicional, lo campesino y lo capitalista. La llave para comprender esta pequeña "ciudad en la ciudad" es analizar el complejo entramado de relaciones sociales que la caracteriza.

A través del análisis de las relaciones que los comerciantes entablan entre sí y con los clientes, se pueden observar peculiares mecanismos de intercambio y reciprocidad, que tienen sus raíces en los mercados tradicionales indígenas.

La mirada etnográfica ha permitido sumergirse por debajo de la superficie económica del mercado, para fijarse en lo que pocos observan: lo no documentado de la vida de los comerciantes, que de hecho son los protagonistas del mercado, y dinamizan este espacio físico, resignificándolo como espacio de interacción social.
\end{abstract}

Palabras clave: Relaciones sociales, relaciones de parentesco, tramos, cultura, economía.

\section{Abstract}

The Oriental Market of Managua is a complex interspace, wherein coexist modernity and tradition, country style and capitalism. The key to understand this small "city within a city," by analyzing this complex network social relationships that characterizes it.

Analyzing this relationship between them and their customers, it can be seen peculiar mechanisms of interchange and reciprocation that belong of traditional indigenous markets.

The ethnographic views allowed immerse in the economic market surface, to take notice in what few observed, what is not recorded about merchant's life, those who are the market protagonists that energizes the physics space, giving a new meaning to this social interaction environment.

Keywords: social relationships, kinship relations, culture, economy.

\section{Introducción}

Hablar de mercados es hablar de tradición, cultura, economía y sociedad. En los mercados se han intercambiado, desde épocas muy antiguas, mucho más que bienes materiales. En la actualidad, la comprensión de las relaciones sociales establecidas en los mercados y la forma en que estas influyen en la organización del espacio físico, en la distribución del trabajo y en los intercambios comerciales es un aspecto esencial para entender su dinámica.

Este trabajo representan un avance de los resultados obtenidos, hasta este momento, de una investigación etnográfica iniciada en el año 2013 sobre el Mercado Oriental de Managua y sus protagonistas: los comerciantes. 
A partir de la realidad cotidiana vivida en este espacio, se pretende reflexionar sobre la importancia de las relaciones sociales en las actividades comerciales desarrolladas en el mercado y las estrategias tejidas para alcanzar sus fines. En su cotidianeidad, los comerciantes interactúan entre ellos y con los clientes, dando vida a un complejo entramado social que merece ser estudiado más a fondo. Para lograrlo es importante analizar estas interacciones sociales dentro de un marco sociocultural amplio.

La investigación busca la comprensión de cada uno de los componentes culturales del mercado, como espacio y como imaginario colectivo. Este concepto cultural está en la raíz de la investigación, ya que el aspecto económico, visible y estudiado en alguna medida, representa una de las expresiones de este complejo entramado sociocultural.

Observando el perpetuo hormigueo humano, que se mueve entre los tramos, los carretones, las canastas y los pasadizos angostos del mercado, --al decir de muchos--, "el más grande de Centroamérica", es preciso explicar cómo se establecen las relaciones sociales a lo interno del mercado, y cómo estas influyen en las lógicas internas y en la estructuración del espacio del Mercado Oriental.

Los estudios etnográficos sobre los mercados son importantes para este trabajo, porque permite establecer con claridad la interrelación existente entre lo tradicional y lo moderno, que de manera ambigua caracteriza la realidad del comerciante y de su entorno socio-cultural.

A diferencia de algunos trabajos de corte sociológico o periodístico que enfocan "desde afuera", las múltiples problemáticas sociales que afligen a los mercados urbanos de las grandes ciudades "del sur" del mundo, este trabajo interpreta la realidad y la dinámica de los comerciantes "desde adentro", como producto de una labor interactiva de dos años de trabajo.
Ese "desde adentro" significa que el proceso de investigación, no se quedó en la contemplación de la superficie económica del mercado, sino el sumergirse dentro de sus entrañas, poniendo atención en lo que en apariencia nadie observa, interceptando lo particular de la cultura, en la mirada y acción de cada uno de los comerciantes. Por tal razón, este informe pretende ofrecer un material teórico metodológico de lo no documentado (Rockwell, 2009:5) de la vida de los comerciantes.

Los antropólogos sabemos que las relaciones sociales influyen en las identidades individuales y colectivas. Tanto la identidad como la alteridad tienen un fuerte componente relacional. Por lo tanto, a través de esta investigación se ha priorizado contestar a la pregunta: ¿Las relaciones sociales, como expresión cultural compleja, son claves en la configuración auto referencial de los comerciantes del Mercado Oriental?

El proceso de investigación evidencia que en la cotidianidad, un sistema complejo de relaciones sociales vincula a todos los actores sociales del mercado, anteponiendo esta dimensión relacional a lo económico.

De hecho, para tener resultados económicos (sean de cualquier índole) los comerciantes

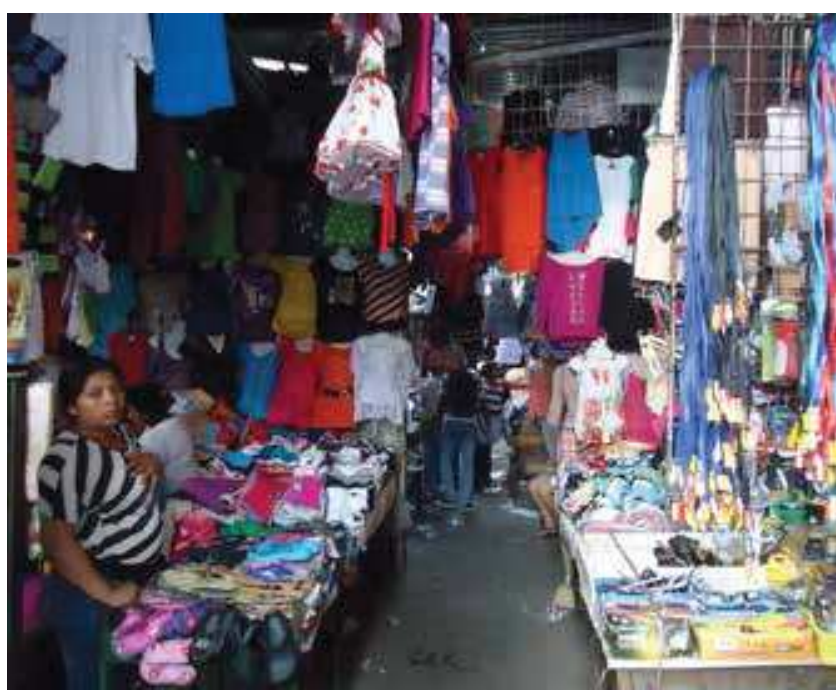


tejen de manera constante una red de relaciones, entre ellos y con los clientes. Es así que, a lo largo del tiempo, en el Mercado Oriental de Managua, se va formando un complejo entramado social, que merece ser descrito e interpretado.

\section{Antecedentes}

\section{Los mercados en Latinoamérica: características socioculturales}

Estudios con enfoques antropológicos en profundidad relacionados con el Mercado Oriental son pocos. Los textos que en Nicaragua se han ocupado de este tema, han sido casi siempre desde la sociología o el periodismo. El interés de estos trabajos se ha concentrado sobre todo en problemas sociales inmediatos que afectan el mercado, específicamente en lo que tiene que ver con la inseguridad. De manera indirecta, queriendo conocer más este espacio, sociólogos y

94 periodistas han terminado, muchas veces, amplificando la imagen de este espacio social, como peligroso, caracterizado por delincuencia, marginación social, hacinamiento y falta de higiene.

Desde la antropología, el antecedente más cercano a este tipo de estudio es el realizado por la antropóloga nicaragüense Elvira Maritza Andino sobre las estrategias económicas domésticas en Nicaragua (1999). En esta investigación, la autora dedica un apartado a las mujeres vendedoras del Mercado Oriental, que según la autora vivían en condiciones precarias. Ella describe el pregonar de cada una de las vendedoras, así como los espacios donde se estacionan, en las esquinas del populoso mercado, exponiendo sus productos con canastas o mesas.

De 1999 hasta hoy se han observado cambios en la realidad del mercado. Sin embargo, un aspecto parece no haber cambiado: el comerciante, quien ha sabido adaptarse a los cambios económicos y las exigencias sociales.
Este sujeto, se integra al sistema económico, estableciendo estrategias sociales que le permitan suplir necesidades inmediatas, como es el contar con el alimento de la familia $\mathrm{y}$ otros gastos complementarios.

Al no contarse con antecedentes específicos a nivel nacional, se utilizarán estudios realizados a nivel regional. Estos han sido publicados, de manera particular, en México y Guatemala, dentro del ámbito de las disciplinas de historia y antropología cultural.

Un aporte importante de estos estudios, es el llamado que hace de conocer la historia de los mercados centroamericanos y preguntarse en qué medida el pasado vive en el presente. Los mercados prehispánicos de América Central tienen un origen mesoamericano (Cancino \& Casas Fernández , 2012, pág. 95), y desde el tiempo precolombino, la población que quería intercambiar y comercializar sus productos se establecían en las plazas de los pueblos.

Los mercados centroamericanos que se conocen en la actualidad, fueron antes plazas libres y de acuerdo a las crónicas (López de Gómara., 1552), tenían estructuras y características similares. En un grupo de Calpulli o pueblo de indios (durante la colonia) se podía observar la siguiente estructura, con sus variantes, de acuerdo a la época: caseríos, casa de los principales artesanos, casa de los comerciantes, casa del consejo de ancianos, casa del jefe de la tribu y la plaza como el centro donde se gestaban las distintas actividades.

En los distintos contextos geográficos $\mathrm{y}$ socioculturales, los mercados se configuraron de acuerdo a la realidad de los comerciantes y de su historia. Bajo esta tendencia, la colonización aportó cambios sustanciales en las formas de vida de los pueblos de Latinoamérica y sin excepción resultó modificado también el mercado (Mejía \& Vázquez Jurado, 2012) 
Durante el período de construcción de la sociedad colonial, los indígenas adaptaron lo que quedó de su sistema económico, después de la conquista y sometimiento, afectando las características socioculturales de los mercados, adaptándolas a las nuevas formas de vida de tipo mercantil. Se podrá observar el cambio en las plazas al aire libre, donde además de exponer sus productos en el suelo sobre telas, se introducen nuevas formas organizativas en esos espacios, incorporando tramos, mesas, canastos de diversos tamaños.

La costumbre de poner las canastas en el suelo, se sigue practicando en la actualidad. Ello es una prueba de la pervivencia de prácticas ancestrales, donde se observa la interrelación entre prácticas comunitarias indígenas y las de tipo mercantil.

Se puede afirmar que después de la colonización, el mercado inicia un largo proceso de transformación. Sin embargo, las prácticas y la representación ancestral indígena, conceptualizado como tradicional y popular en la actualidad, no han desaparecido, conviven con prácticas mercantiles, propias del capitalista moderno.

\section{Aspectos conceptuales que enmarcan el trabajo}

El mercado tradicional a lo largo de su historia ha estado estrechamente vinculado con el mundo rural. Este mundo ruraltradicional,

(...) ha sido regulado a lo largo de su historia por una relación de reciprocidad, redistribución e intercambio (Polanyi, 1944). Con la irrupción de la modernización de la agricultura, a este triángulo eco-compatible ha sido extrapolada una de las esquinas: el intercambio y a partir de este, ha sido reelaborado el todo. Ha sido realizado un reordenamiento en el cual la ganancia a través del intercambio se ha convertido en el ethos de las relaciones alimentarias (Bonino, 2013, p. 3).

Cuandoseanalizaelmercadolatinoamericano contemporáneo, y en nuestro caso el Mercado Oriental de Managua, es necesario indicar que algo muy parecido ha ocurrido aquí también. La ganancia a través del intercambio ha venido ocupando un lugar cada vez más hegemónico. Sin embargo, no ha podido eliminar del todo las lógicas de la reciprocidad y de la redistribución, ya que estas dos dimensiones siguen siendo parte de la cultura de los comerciantes del mercado y se manifiestan en las relaciones sociales que ellos establecen entre sí.

En la identidad del comerciante urbano permanecen vivos, aunque de manera oculta, elementos de esta cultura indígena y campesina que el sistema capitalista no ha podido eliminar. Entiéndase la identidad como "la cristalización al interior de un individuo de las relaciones sociales y culturales en el seno de las cuales él/ella está comprometido/a y a las cuales es inducido/a a reproducir o a rechazar (Godelier, 2010, p. 25).

Precisamente, el comerciante cristaliza de forma subjetiva esas relaciones sociales, que se observan aglutinadas en redes informales de solidaridad. Los comerciantes utilizan estas redes para colaborar entre sí y obtener beneficios económicos, en una lógica de reciprocidad.

Hablando de reciprocidad, se hará referencia a dos fenómenos, a menudo relacionados a la circulación diferida de bienes y a un constructo ideológico que afirma la obligación de la devolución de forma equilibrada.

La reciprocidad [se puede definir] como el intercambio normativo y continuo de bienes y servicios entre personas conocidas entre sí, en el que entre una prestación y su devolución debe transcurrir un cierto tiempo, y el proceso de negociación de las partes, 
en lugar de ser un abierto regateo, es más bien encubierto por formas de comportamiento ceremonial. Las partes inter actuantes pueden ser tanto individuos como instituciones (Alberti \& Mayer, 1974).

Este aspecto es muy importante para entender la naturaleza de las relaciones sociales que se viven en el mercado. La relación se gesta primeramente desde la familia, después pasa a un grado mayor, la asociatividad, donde las personas se relacionan para fines de trabajo, y esto permite que en los mercados existan asociaciones, las cuales consienten en la unión de personas con características similares para velar por sus intereses comunes, buscando soluciones más específicas a sus problemas. Por lo tanto, dos conceptos claves merecen ser profundizados: el concepto de parentesco y el concepto de asociatividad.

Levi-Strauss (1969, pág. 195) define las estructuras elementales del parentesco como "los sistemas cuya nomenclatura permite determinar en forma inmediata el círculo de los parientes y el de los Allegados". Según este autor, todo círculo social se gesta por medio de las bases familiares orientando el comportamiento social del individuo. Siguiendo ese criterio, la base familiar influenciará al nuevo integrante de la familia para que responda bajo la lógica y dinámica del resto de sus parientes. Otro aporte importante es dado por Morgan (1877), quien acuñó la idea de lazos de parentesco como "la vinculación de madre e hijo, de hermano y hermana y de abuela y nieto, se ha podido establecer en todas las épocas..." (p. 409).

Los lazos de parentesco son sumamente importantes para entender la organización de los espacios en el mercado, la distribución del trabajo al interno de cada familia, el paso de propiedad de una actividad comercial, la transmisión inter generacional de conocimientos locales y el aprendizaje de prácticas como saberes específicos de actividades comerciales. Esta dinámica

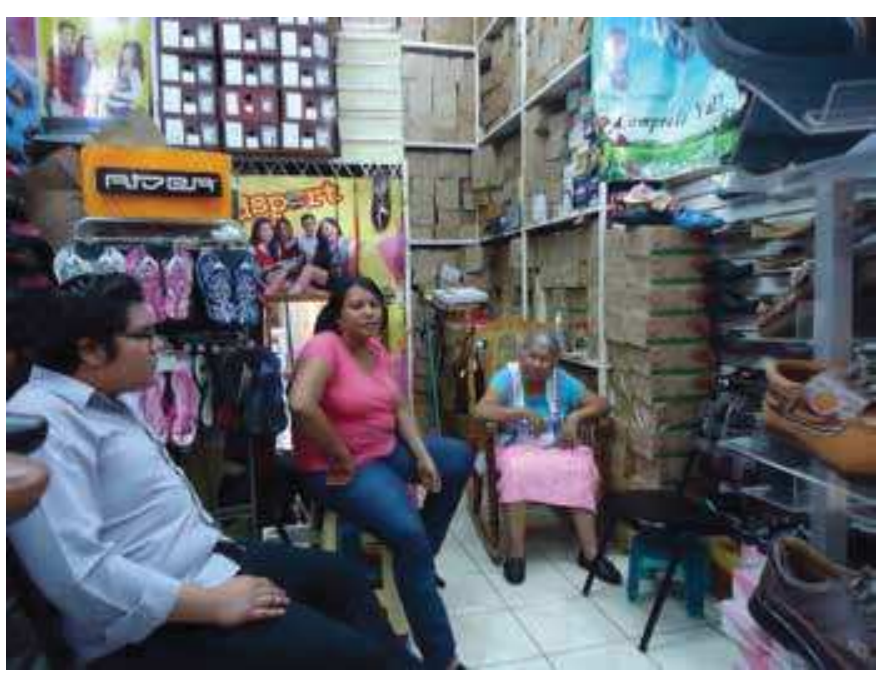

colectiva e integral, permite la vigencia de las principales características socioculturales de los comerciantes como las anteriormente mencionadas.

La familia no es la única forma por medio de la cual se coopera con un fin común, a lo interno del mercado. De hecho, según Plattner (1991), "las asociaciones parecen ser una de las formas con las cuales las granjas familiares enfrentan los costos crecientes" (pág. 384), procurando vender sus productos sin perjudicarse mutuamente. La decisión de asociarse es voluntaria y los actores sociales "generan un nosotros y un nivel identitario al momento de coparticipar de la realización y satisfacción de un objetivo necesidad convocante..." (Aguirre \& Pinto, 2006, pág. 85).

Para terminar este apartado, es importante, recordar lo mencionado arriba, los cimientos del mercado, desde sus orígenes tradicionales hasta la ambigüedad existente entre tradición y modernidad, han sido un complejo entramado de relaciones sociales. $\mathrm{Su}$ comprensión debe de reconocer las características socioculturales propias de los comerciantes, quienes son los protagonistas principales del mercado, y que dinamizan este espacio físico, resinificándolo como espacio de interacción social. 


\section{Metodología utilizada}

La investigación en curso expuesta en artículo, se realizó durante el primer semestre de 2013, mediante un trabajo de campo de dos semanas intensivas en el Mercado Oriental de Managua. Esta fue realizada bajo el enfoque cualitativo de investigación y como método de estudio se utilizó el etnográfico. La etnografía (Guber, 2001)se basa en la observación, descripción e interpretación del contexto y de los sujetos que se pretende estudiar. Se aplicaron entrevistas abiertas, a profundidad y conversaciones informales.

La observación participante fue un elemento esencial que permitió el análisis del contexto, es decir la relación entre los sujetos y el espacio físico y su interacción social. Los comerciantes del Mercado Oriental, aunque parezcan ser abiertos y accesibles, socialmente hablando, no lo son cuando de entrevista se trata. Son desconfiados porque confunden al investigador con un periodista. Sin embargo, una actitud empática y respetuosa (relacionada con la convivencia diaria), puede ayudar al etnógrafo a establecer relaciones simétricas con los protagonistas de su investigación, como he podido apreciar en mi personal experiencia.

Observando a los comerciantes, escuchando sus palabras y compartiendo con ellos algunos momentos de su rutina cotidiana, he podido acercarme a su realidad y comprender un poco más sobre la compleja red de relaciones sociales en la cual se desenvuelven a diario.

\section{Resultados}

\section{El mercado oriental: entre el pasado y el presente}

El Mercado Oriental considerado por alguno como el más grande de Centro América tiene una extensión aproximada de 52 hectáreas, en las que se ubican tiendas, distribuidoras, comedores, y vendedores fijos y ambulantes- eventuales. Este mercado creado en la década del 40 del siglo XX, experimentó un crecimiento vertiginoso a raíz del terremoto de 1972, cuando Managua y sus alrededores quedaron completamente en ruinas y los viejos mercados San Miguel (Central) y Bóer desparecieron en los escombros.

Se calcula en decenas de miles las personas provenientes de la capital, el interior del país y extranjeros que visitan el Mercado Oriental. Para quienes no lo han visitado, la primera experiencia les puede parecer traumática, por las complicaciones para movilizarse en su interior. Para acceder al mercado se puede hacer por medio de las distintas entradas y salidas, las cuales en sus inicios puede desorientar, dado que los tramos y los pasadizos angostos y abigarrados de objetos y personas, sufren a menudo remodelaciones o reconstrucciones en su estructura y lógica de uso.

Testimonio de la asombrosa expansión del mercado es la de Doña Marillita Urbina, anciana octogenaria, considerada una pocas sobrevivientes de las fundadoras de este populoso centro comercial. Por lo general ella se encuentra sentada en su tramo de venta de zapatos, donde pasa todo el día. No se siente a gusto estar en su casa, le hace falta el ambiente del mercado. Al recordar los inicios del mercado, sus palabras evocan una imagen muy distinta a la que estamos acostumbrados: "Hace mucho, cuando venía con mi mama, esto eran tres galerones pequeños y se parqueaban los camiones a vender lo que traían del norte y sur del país" (María Urbina 16/04/13).

Durante la conversación, doña Marillita recordaba los momentos de muchacha cuando comenzó a trabajar en el mercado Bóer y Mercado Central, hasta que se establecieron en el Mercado Oriental. Con orgullo afirma que conoció el Oriental en sus inicios y ha visto su expansión hasta lo que en la actualidad es, un centro de gran importancia para la economía popular del país. 
El proceso de expansión del Mercado se aceleró con mayor fuerza durante el periodo neoliberal (1990-2006). En los primeros años de la década de los 90 (gobierno de doña Violeta), se experimentó un proceso drástico de reducción del aparato del estado, siguiendo las recomendaciones de los organismos internacionales como el Banco Mundial y el FMI (conocido como ESAF) (Gamboa, 2007). Estos nuevos desempleados no tuvieron otra opción que buscar nuevas soluciones a la falta de empleo y urgentes necesidades familiares.

Muchos de estos miles de desempleados, al encontrar como única y rápida forma de empleo, el establecerse en el mercado, propiciaron la expansión del mismo, de forma desordenada. Desde ese momento (principios de la década de los 90) y por la forma en que se dio el crecimiento, sin regulación alguna, este espacio capitalino es considerado en la actualidad como uno de los sitios de mayor vulnerabilidad e inseguro de la ciudad.

\section{Redes sociales y organizaciones espacial del Mercado}

En el Mercado se pueden encontrar tres tipos de expresiones sociales organizativas (que estructuran zonas territoriales), cuyas formas de gestión se manifiestan de manera concreta por medio de redes. Configuradas y gestionadas por los comerciantes, estas redes se estructuran a partir de grupos afines o por interés comunes. Están los "grupos aliados", los del "Calvario" y los del "Callejón de la muerte", o en algunos casos, --como una cuarta expresión-- un comerciante que tiene sus amigos en la misma zona.

Las razones por las cuales se estructuran estos grupos en alianzas, pueden ser múltiples. La más lógica es encontrar seguridad, satisfacer sus expectativas de comerciantes, estas últimas se manifiestan en un abanico complejo de interés, desde sentirse orgánicamente integrada al grupo por medio del ejercicio de actividades comunes, hasta tener conciencia de su pertenencia a una zona donde se venden los mismos bienes o productos.

En este espacio público denominado Mercado, sus miembros (vivanderas o comerciantes) sienten la necesidad de contar con "aliados" y definirse frente a los "otros". Las expresiones más comunes que suelen manifestar sobre el tema son: "Aquí todos somos compañeros. Yo trabajo al frente, pero como no estoy vendiendo mucho, le ayudo al compañero a vender". (Sergio García, 19/04/13)

"Ayudar" a su compañero implica proximidad y reciprocidad. Un comerciante ayuda a su vecino al no atender su tramo, debido a razones de ausencia temporal. Este comerciante, sabe que en algún momento que él se ausente de su tramo, es probable que cuente con el apoyo del compañero a quien le atendió su negocio anteriormente. De esa manera se institucionaliza una práctica de reciprocidad que se reproducirá entre ellos.

Precisamente, estas relaciones entre comerciantes tienen que ver con la composición misma del Mercado, el cual permite que cierto grupo de comerciantes establecidos en zonas bien delimitadas, puedan establecer $\mathrm{y} / \mathrm{o}$ fortalecer relaciones de intercambio, amistad, creando lazos sociales mucho más complejos. De esta manera, se consolida de manera paulatina una red cuyas expresiones principales en las relaciones, están mediadas por su carácter directo (comerciante de una zona con otra) $\mathrm{o}$ indirecto (comerciante que obtiene algo de otro comerciante pero no de manos de él, sino de terceros).

\section{Relaciones de parentesco y tipología de los tramos}

Las relaciones de parentesco tienen una importante implicación en la construcción de las redes sociales dentro del Mercado. Los 
lazos familiares facilitan el establecimiento de relaciones entre los comerciantes, dado que por medio de este mecanismo cultural, --de pertenecer a una familia conocida-- se da una identificación rápida y segura entre los vendedores en ese espacio.

En los mercados existe un patrón común: las personas tienden a trabajar dentro de grupos familiares. Núcleos familiares conforman su propio negocio, cuyos trabajadores son -en su mayoría-- los mismos miembros de su familia, sea nuclear o extendida. Este tipo de relaciones consanguíneas conforman un tipo estructurado de tramo.

El gráfico 1 muestra la estructura social de la organización de los tramos. Es oportuno analizarlo desde el punto de vista jerárquico familiar, puesto que los tramos están encabezados generalmente por el padre, y en caso que no exista, la madre ocupa la posición

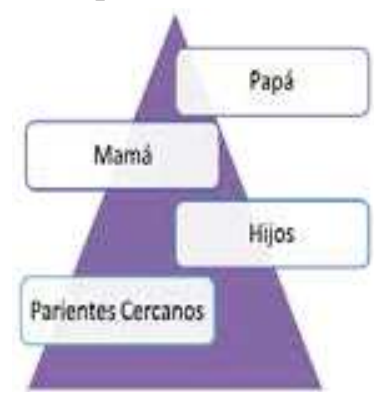

1Tramo simple o familiar de jefe. De forma tal que los roles de trabajo están configurados $\mathrm{t}$ e $\mathrm{n}$ i e $\mathrm{n} \mathrm{d}$ o como cabeza del negocio al padre o la madre.

Las relación familiares (consanguínea) hay un traspaso que sobre pasa el aspecto relacionado con los bienes materiales. En ello también intervienen valores socio-culturales, que tienen que ver con ética, moral y actitud ante la vida.

Además de los tramos organizados por relaciones consanguíneas, se encuentran los tramos estructurados por afinidad. Esta expresión organizativa, hace referencia a la incorporación en calidad de trabajadores a parientes dentro de la familia extendida (cuñados, suegros), tutores o amigos (Ver gráfico 2).

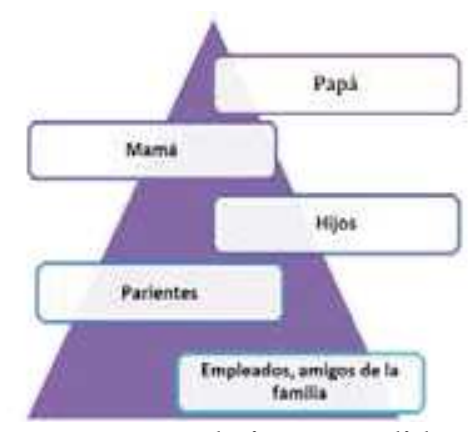

2 Tramo secundario o extendido

Desde hace mucho tiempo existe una tendencia de organización de los tramos con miembros de la familia donde confluyen tres generaciones. Abuelos (en algunos casos son los fundadores o herederos del negocio de sus padres o familiares), padres e hijos. Esta cadena aumenta porque pueden estar los hijos de los hijos. Este tipo de tramos son extendidos o secundarios.

Las actividades y roles en este tipo de estructuras de administración de los tramos tienen mayor complejidad. En este caso, la posición de jefe la ocupan el padre, la madre y hasta los hijos. Esto se debe a que existen más miembros en este tramo, como los parientes y empleados no consanguíneos.

El patrón padres-hijos es fundamental en el desarrollo de los mercados. Los padres, dueños de tramos o negocios quieren asegurarse que éste quede en la familia. En otras palabras, las relaciones de parentescos permiten que los hijos se involucren de manera directa y sistemática en las actividades comerciales, como forma de aprendizaje gradual que asegure el relevo generacional. De allí la expresión de los dueños del tramo: "algún día será de ellos". Como menciona uno de los informantes: "Mis abuelos fueron comerciantes y mis padres también, junto a mis tíos" (Sosa, 19/04/13).

Las relaciones de parentesco repercuten también en la distribución de las actividades dentro del tramo. Esta distribución se expresa es el encargado de recibir el dinero, de 
publicitar el producto o los servicios y atraer clientes (pregón) y atender a los clientes.

Hay que recalcar que quienes poseen tramos secundarios pertenecen a los sectores sociales más favorecidos del mercado, dado que únicamente si se cuenta con cierta capacidad económica, se puede contar con empleados. Esta observación es importante porque se debe de tener conciencia que a lo interno del Mercado existen diferencias de clase y al tramo secundario se asocian los de mejores condiciones económicas, con un estatus social elevado.

\section{Distribución del trabajo a lo interno de los tramos}

Tanto en los tramos simples como en los secundarios, toda la familia trabaja. Sin embargo, existe una distribución del trabajo coordinada por el padre, quien se encarga de la distribución de las tareas para cada uno de los miembros en su condición familiarempleado. Los miembros de la familia - sobre todo en los tramos simples- no perciben una remuneración formal, ya que su empeño es visto en función del aporte a la alimentación de la familia, según criterios de subsistencia. En el caso de un tramo más grande (extendido o secundario), se le provee al personal, sea familiar o no, de una remuneración establecida.

Las formas por medio de las cuales se distribuye el trabajo, responden a normas cotidianas donde las relaciones laborales con las familiares se traslapan, sin que exista una clara división entre ambas, incluso sin que medie necesariamente jerarquía alguna. Un ejemplo en ambos tipos de tramos se puede ver en quien maneja la recolección del dinero, en el marco de las transacciones que se establecen, $\mathrm{y}$ donde pueden participar varias personas. La representación simbólica del "delantal", hace la diferencia, ya que identifica con claridad al "jefe" del tramo.

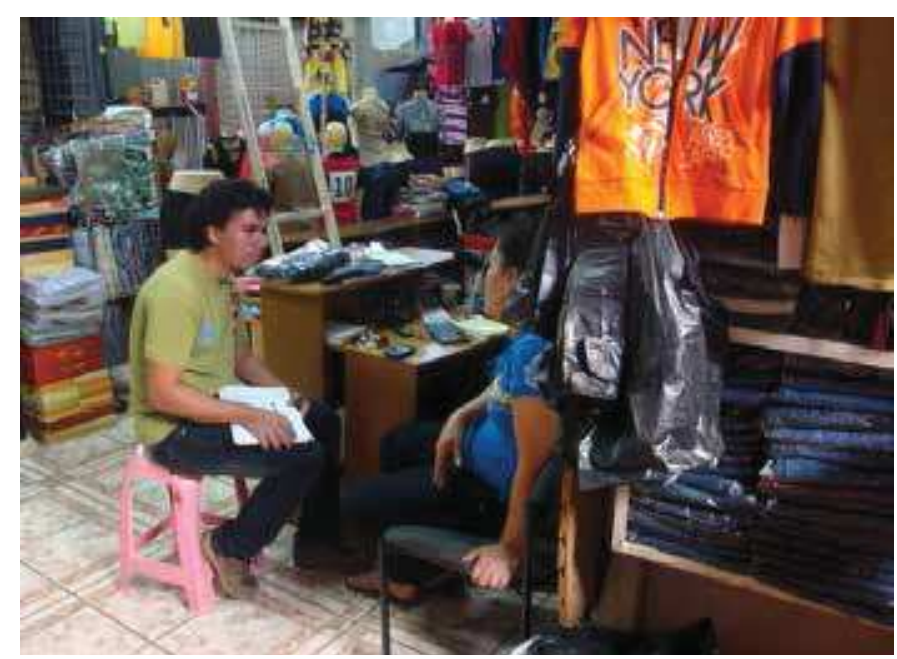

Para completar las observaciones sobre la distribución del trabajo, es útil retomar el comentario de la informante Andrea Meneses, quien señala: "En este tramo todos trabajamos. Uno se dedican a vender y otros buscan el producto del cliente." (Meneses 17/04/13). Esto demuestra que las personas ya están organizadas en sus trabajos. Pero, ¿cómo lo hicieron? ¿Lo aprendieron? ¿Cómo?

Las personas al interactuar socialmente hablando, transmiten sus conocimientos de forma oral (y escrita), la cual está sustentada en experiencias prácticas, las cuales se transfieren también de manera simultánea. Toda persona desde su infancia observa las actividades que hacen sus padres a quienes imitan inicialmente, tanto dentro del hogar como de fuera de él. Este tipo de aprendizaje por imitación es común en culturas tradicionales, cuya base de reproducción es por medio de sistemas de educación "informal".

La distribución del trabajo en el mercado Oriental, responde a lógicas de carácter social, donde las familia en sus diferentes expresiones, desarrollan una diversidad de labores sin las cuales difícilmente se podría caracterizar a este importante espacio público de la capital. Un razonamiento pragmático podría sugerir que las personas que se mantienen en este lugar, únicamente 
piensan en ganar el sustento diario, sin embargo las relaciones de diversas índoles que se tejen y entretejen, indican actividades sociales y culturales donde no media ingreso o transacción económica alguna. No es casual que la alcaldía, a la par que crea centros recreativos, jardines infantiles, establece centros de salud.

\section{Relaciones entre comerciantes: intercambio y reciprocidad}

Puede pensarse que toda actividad comercial, necesita de redes sociales que favorezcan el desarrollo del negocio. Por lo tanto, los comerciantes buscan medios para relacionarse con otros colegas con el fin de retroalimentarse sobre el quehacer cotidiano en que están envueltos. En ese proceso, se van estructurando alianzas que ayudan a mitigar deficiencias o superar problema de venta, agenciarse nuevos clientes $\mathrm{o}$ atenciones temporales de sus negocios. La informante Sandra Morales señala: "Las personas aquí tienen buena relación. De lo contrario no podrá salir adelante. Es importante llevarse bien con los demás para que nos vaya bien en el negocio también" (Sandra Morales, 21/04/13).

Sin embargo, las relaciones establecidas entre los comerciantes de una zona y otra, están vinculadas a un individuo que cumple el rol de conector social entre los comerciantes, aún cuando estos se encuentren a larga distancia. A este individuo se le llama popularmente "Corredor". Su función es la de conectar desde el punto de vista social los tramos, dado que el ejercicio de esta, permite que todos los tramos del mercado le conozcan. Como menciona uno de los informantes: " $E l$ ser corredor es ser un comodín, maneja los precios del mercado, todos lo conocen". (Dennis Urbina 21/04/13).

Con la finalidad de que se comprenda las funciones del Corredor, damos a conocer un ejemplo. Si el dueño de un tramo, donde es empleado el Corredor, no tiene un pantalón, éste último debe de ir a prisa a otro tramo conocido -puede ser de un familiar o amigo del dueño- pedir "prestar" el pantalón y así lograr concretar la venta. El "préstamo" se vuelve una forma de intercambio, pero a su vez implica reciprocidad. En otra ocasión, el amigo buscará la manera de regresar el favor.

Otra expresión donde se percibe la reciprocidad por medio de los intercambios, es el caso de los "préstamos de clientes", patrón común dentro de los mercados. El hecho de "prestarse un cliente", implica que la persona se sienta moralmente obligada a regresar el mismo favor. No obstante, esta forma de intercambio se ve condicionada por relaciones sociales pre-establecidas entre los miembros de los distintos tramos: se llevará al cliente a un tramo de un familiar o amigo.

Es importante mencionar algunas normas no escritas que facilitan las prácticas de reciprocidad entre los comerciantes del Mercado Oriental:

- Cuidar los tramos de los vecinos: es una regla que se cumple por el grado de confianza existente entre ellos. Su ruptura pudiera darse si una de las partes falte al lazo de amistad.

- Generalmente existe reciprocidad entre comerciantes que son familiares o amistades cercanas.

- La confianza entre los involucrados permite que la reciprocidad entre ellos sea mínima o máxima.

- Para que exista un primer acto de reciprocidad, las partes deben al menos conocerse, aunque no se hayan hablado antes.

- Si en el tramo la madre trabaja en un área específica y le pide al marido que le ayude, éste puede recibir la colaboración de ella más adelante en sus casas.

La consideración de reciprocidad dentro del mercado implica en muchos sentidos ayudar, prestar, servir, etc. Los involucrados colaboran con las personas que tienen un alto grado de confianza. Asimismo, coordinan 
redes sociales que van a permitir resolver las necesidades cotidianas, por medio de los lazos que tiene con otros comerciantes.

La asociatividad, formaliza las prácticas de ayuda recíproca, incidiendo en las relaciones sociales establecidas dentro del mercado. En un contexto tan complejo y extenso como el Mercado Oriental, las personas sienten la necesidad de asociarse con el fin de encontrar apoyos mutuos, intercambiar clientes, ayudarse a vender sus productos.

Sin embargo, el tema de la asociatividad es complejo y merece ser analizado más a fondo en otro espacio, ya que el trabajo de campo ha evidenciado muchas contradicciones al respecto. De hecho, no todos los comerciantes se identifican con las asociaciones existentes en el Oriental. En este trabajo se ha limitado a evidenciar las relaciones establecidas fuera de estas organizaciones.

\section{Relaciones entre comerciantes y clientes}

Otras expresiones de intercambio son aquellas que se establecen entre los clientes y el comerciante. El cliente busca la manera de llevarse un producto al precio más favorable, empleando la estrategia del regateo, dando indirectamente al comerciante información de cómo están los precios en otro lugar.

Santos Calero, uno de los informantes menciona que: "el mismo cliente transmite el valor del producto en otros tramos" (Calero 17/04/2013). De hecho el consumidor se convierte en el transmisor de la información de tramo en tramo, y a cambio procura obtener quizás el mismo producto a menor precio.

Este es uno de los aspectos que influyen en las relaciones entre clientes y comerciantes. Otro que merece ser descrito y analizado tiene como protagonista al comerciante. Relacionarse con los clientes es un arte y los vendedores deben establecer estrategias apropiadas para convencerlos a acercarse y a comprar en sus tramos. Aprende a ser sociable en los mercados, es de vital importancia para tener un contacto inmediato y espontáneo con los clientes. La comerciante doña Ligia García comenta sobre este tema: "El vendedor es social, antes era difícil que esto se notara bien, porque no habia una buena organización, pero ahora ya cambió eso y hay una mejor relación entre los comerciantes y la población". (Ligia García, 20/04/13)

De lo anterior, se puede decir que los comerciantes tienden a formular estrategias específicas de venta. Estas implican mercadear de una forma sencilla y directa sus productos buscando llamar la atención del cliente, lo cual es una característica propia de la cultura de estos mercados. Según el informante Wilmer Cruz: "Ellos ofrecen sus productos cantando, su filosofía es esa". (Wilmer Cruz, 16/04/13)

Los comerciantes cantan sus productos, llamando la atención de sus clientes: Hay tomate cebolla, chiltomas, ¿Qué vas a querer amor? Sin embargo, no se trata solo de cantar, sino de utilizar una estrategia convincente, lograr que el cliente le compre. Uno de los informantes hace referencia a este tema: "yo enamoro a mis clientes y después son mis marchantes" (Andrea Meneses: 17/04/13)

Las personas que se vuelven clientes fijos de un tramo se les llaman "marchante". Cuando estas personas regresan al mercado a realizar sus compras, vuelve a visitar al comerciante con fines de compra. Esta estrategia de conservar al cliente y este mantener la fidelidad con el establecimiento, conlleva el cultivo de un tipo de relaciones sociales de amistad. Como dicen los comerciantes: "cada vendedor tiene su marchante" (Wilmer Cruz: 16/04/13). Para que esta condición se alcance, es necesario un lento y progresivo proceso de acercamiento y convencimiento.

Desde que llega el cliente por primera vez, el comerciante empieza a cantarle sus 
productos, le habla, enamora, incluso le toma de la mano. Esas variadas formas de llamar la atención, representan la primera fase del convencimiento. Cuando el cliente se acerca al tramo, la siguiente etapa es venderle y darle una buena impresión en términos de comunicación y atención. Luego de que las relaciones de afinidad social han sido establecidas de manera correcta (construyendo un tipo de empatía) el cliente pasa a ser un marchante de ese comerciante.

De esta manera, merced a la especial mirada antropológica, se puede poner en perspectiva, la naturaleza de las relaciones sociales dentro del proceso de compra-venta. El comerciante no es un simple individuo pasivo, en un espacio congestionado, ruidoso, sino un sujeto activo, protagonista también del complejo entramado social y cultural que caracteriza el mercado.

\section{Discusión}

El Mercado Oriental es un espacio ambiguo, entre lo moderno y lo tradicional, donde se manifiestan prácticas discursivas mercantiles y culturales con fuertes reminiscencias campesino y otras avanzadas de tipo capitalista. En Nicaragua han ido despareciendo de los mercados eminentemente tradicionales (aquellos donde median relaciones mercantiles simples, incluyendo el trueque). No obstante, es oportuno destacar el rol protagónico de las prácticas sociales en la configuración de la identidad de los comerciantes.

Los comerciantes se relacionan o asocian entre sí, porque necesitan establecer alianzas "estratégicas". Polanyi (1944) reflexionó acerca de la transformación de las necesidades en el campesinado. En este caso, se utiliza este planteamiento para indicar que los comerciantes, por la heterogeneidad misma en la que están inmersos, han transformado las estrategias de alianza: ya no se trata de establecer una simple relación social para hablarle al vecino, sino que necesita tener un grupo con el cual se identifica, con el cual se siente cómodos y realiza actividades dentro del mercado entidad como un espacio sociocultural.

Godelier (2010) indica que los individuos interiorizan las cosas a las que están familiarizados. Sin embargo, por mucho tiempo se han dado transformaciones sustanciales en las identidades, las cuales se tejen y entretejen en el día a día de de los comerciantes. Estas transformaciones pueden percibirse, haciendo un recorrido, desde la época colonial, hasta la actualidad. Se observa también la persistencia a través del tiempo de ciertos patrones tradicionales, como la capacidad de relacionarse con otros individuos por medio de mecanismos específicos de intercambio y reciprocidad y hacer más productiva su labor de comerciante.

Según Lévi-Strauss (1871, pág. 200), --y tratando de guardar las distancias de las comparaciones y experiencias-- "la distribución [del trabajo] se hace dentro de los límites del grupo de parentesco" y los lazos familiares determinan roles dentro de un grupo o espacio social. Los resultados de esta investigación muestran un escenario más complejo. Coincidimos con Strauss, que las relaciones sociales parten de la familia, pero se extienden hasta los comerciantes vecinos e incluso a los que no están cerca, en este caso por medio del "Corredor".

El entramado social encontrado en el Mercado Oriental conserva elementos socio-culturales cuyas raíces están firmemente sujetas a los mercados tradicionales indígenas. Las estrategias de mercado, como el cantar sus productos, vender con canastas en el suelo o establecer relaciones de intercambio y reciprocidad con familiares y otros aliados son reminiscencias claras de una tradición ancestral presente aún en la vida cotidiana del mercado.. 


\section{Conclusiones}

En conclusión, el Mercado Oriental de Managua está divido en tres zonas las cuales poseen características específicas. En estas zonas existen comerciantes que tienen distintos orígenes: campesino de la periferia de la capital, el campesino que emigró de otro departamento y los comerciantes urbanos propiamente.

Las formas de organización han variado notablemente a lo largo del tiempo y de generaciones. Las formas en que se estructuran las relaciones sociales en una sociedad determinada, son esenciales para entender los mecanismos organizativos. De hecho, las distintas formas de relacionarse socialmente dentro del Mercado Oriental han determinado actividades y por lo tanto configurado el espacio sociocultural, negando con ello la visión de un espacio físico impersonal, de "tránsito", "temporal" y sometido a las reglas inflexibles de la compra-venta.

El dilucidar la compleja trama de relaciones sociales establecidas en el Mercado Oriental, son claves para la comprensión de las estructuras organizadas dentro del mercado, conocidas como tramos. Al respecto, se evidenció cómo estos tipos de relaciones diferencian dos tipos de tramos: simple o familiar y secundario o extendido.

Para finalizar, hablar de mercado, es hablar de relaciones sociales complejas que se encuentran emparejadas con la necesidad inmediata de vender productos para el sustento diario, para el caso de la mayoría de comerciantes pequeños y medianos. Los datos etnográficos han mostrado que el Mercado Oriental más que un espacio económico, es sobre todo un espacio de relaciones sociales y de identidad cultural.

\section{Referencias bibliográficas}

Alberti, G., \& Mayer, E. (1974). Reciprocidad e intercambio en los andes peruanos. Lima: IEP ediciones.

Andino, M. (1999). Elementos de la Antropologia para el estudio de la economia nicaraguense: Estrategias Economicas Domésticas. Managua: Factultad de Ciencias de la Eduacion y Humanidades. UNANManagua .

Anguera, M. T. (1986). Investigación Cualitativa. Educar , 1-28.

Auge, M. (1996). Los no lugares, Espacios de Anonimato. España: Gedisa.

Baztán, A. A. (1995). Etnografia: Metodlogía de Investigación Cualitativa. Dialnet, $1-25$.

Bonino, J. C. (2013). El derecho a la alimentación entre ecologia campesina y producción agroindustrial. Rebelión, 1-9.

Cancino, Y. A., \& Casas Fernández, A. (2012). los mercados tradicionales del valle de tehuacán-cuicatlán: antecedentes y situación actual. méxico : Nueva Antropologia .

Castells, M. (1972). La cuestión urbano. Mexico: Siglo XXI.

Costa, C. (2014). Ensayo de Etnografia. Asignatura Introduccion a la Antropologia - Managua : Departamento de Antropologia UNAN.

Fabietti, U., \& Remotti, F. (1997). Diccionario de Antropologia. Italia: Zanichelli.

Firth, R. (2010). La Organización social y el cambio social. Revista de ciencias sociales de Universidad Iberoamericana, 164.

Galeano, J. R. (2010). Mercado Oriental: Riesgo. s.n, 2.

Gamboa, M. (2007). Flexibilización del Mercado Laboral en Nicaragua. Una aproxiamción a su medición y un aporte al debate sobre sus implicaciones de género. Managua: UNIFEM.

Godelier, M. (1974). Antropoloía y Economia. Barcelona: Anagrama.

Godelier, M. (2010). Comunidad, sociedad, cultura. Tres claves para comprender 
las identidades en conflicto. Cuadernos de Antropología Social No 32. , 13-29.

Goldin, L. R. (1987). DE PLAZA A MERCADO: La expresión de dos sistemas conceptuales en la ogranización de los mercados del occidente de Guatemala. México: Anales de Antropologia.

Gómara, F. L. (1555). Historia General de las Indias y el Nuevo Mundo. Zaragoza: Nuevos Mundos.

Guber, R. (2001). La Etnografia. Metodo, Campo y Reflexividad. . Bogota: Norma.

Hammersley, M., \& Atkinson, P. (1994). Etnografía. Métodos de investigación. Barcelona: Paidos.

Hannerz, U. (1987). La exploracion de la Ciudad. Hacia una antropologia urbana. México: Fondo de Cultura Económica.

Instituto Nicaraguense de Estudio Territoriales (INETER). (2009). METODOLOGIA PARA LA ELABORACIÓN DE LOS ESTUDIOS DE ORDENAMIENTO TERRITORIAL. Managua: s.e.

La Prensa. (10 de Noviembre de 2013). Basura a tope en el Mercado Oriental. El Diario de Los Nicaraguenses.

Levi-Strauss, C. (1969). Estructuras Elementales del Parentesco. Barelona: Paidos.

López de Gomera., F. (1552). Nicaragua. Zaragoza: Colección Cultural.

Margulis, M. (2009). Sociologia de la Cultura. Buenos Aires: Biblos.

Meillasoux, C. (1977). Mujeres, Graneros y Capitales. España: Siglo XXI.

Mejía, V. A., \& Vázquez Jurado , M. A. (2012). MERCADO "JUÁREZ": CULTURA Y TRADICIÓN . México : antropoformas Nuevas Épocas .

Moreno, I. (1997). Antropologia del Trabajo. Barcelona: Revista Andaluza.

Organización Mundial de la Salud . (2002). Informe Mundial sobre violencia y salud. Whashintong D.C: OMS.

Pérez, J. M. (2005). El arca de Noe del Mercado Oriental. Revista Enlace.

Pérez, M. G. (2013). Delitos de mayor impacto y frecuencia en cinco municipios de Nicaragua, del 2000/2011. Managua:
IEEPP.

Plattner, S. (1991). Introducción a la Antropología Económica. Mexico: Editorial Patria.

Polanyi, K. (1944). La Gran Transformación. Los origenes politicos y económicos de nuestros tiempos. México: Fondo de Cultura Económica.

RiuNet. (Agosto de 2013). Mercadeo en la Internet. Recuperado el 22 de Septiembre de 2014, de Defincion y Objetivos de Marketing en la Internet: http:/ / riunet.upv.es/bitstream/ handle/10251/8636/PFCMarketing. pdf

Rodgers, D. (2001). Haciendo del Peligro una Vocación: La antropología, la violencia, y los dilemas de la observación participante. Revista Española de Investigación Criminólogica. REIC, 1-24.

Rota, J. A. (2009). El concepto de Cultura en Antropologia Contemporanea. Consello da Cultura Galela, 10.

Rugama, H. M. (4 de Septiembre de 2013). Detienen reordenamiento en el Mercado Oriental. El Nuevo Diario.

Sánchez, C. S., Hernández, P. O., \& Ortiz Pedraza, F. (2005). Estudios de Antropologia Biologica. Volumn XII. Mexico : Conaculta.

Sanmartín, R. (1993). Identidad y Recreación Horizontes culturales e interpretación antropológica. Barcelona: Editorial Humanidades.

Signorelli, A. (1999). Antropologia Urbana. Barcelona: Anthropos Editorial.

Vado, M. A. (s.d de s.m de 2001). Textos_Web_ UCA. Recuperado el 21 de Septiembre de 2014, de Textos_Web_UCA: http:// www.bvsde.org.ni/Web_textos/ UCA/UCA0001/mercados.pdf

Valenzuela, H., \& Molina, L. (2006). Invitación a la Antropología Económica. Barcelona: Edicions Bellaterra.

Velasquez, J. R. (2001). El Trabajo etnografico. Un olvido de la antropologia fisica. Estudios de Antropologia Biologica, 635653.

Witzel, A. (1985). Investigación Cualitativa. Scielo. 